\title{
Leaders
}

\section{Do mouthguards prevent concussion?}

One of the most commonly held myths in sports medicine is the premise that wearing a mouthguard will prevent concussion. The origins of this contention are obscure, but an evidence based review of the scientific support for this concept has not been previously published.

\section{History}

Mouthguards or "gum shields" were originally developed in 1890 by Woolf Krause, a London dentist, as a means of protecting boxers from lip lacerations. Such injuries were a common and often disabling accompaniment of boxing contests in that era. ${ }^{1-3}$ These gum shields were originally made from gutta percha and were held in place by clenching the teeth. Philip Krause, his son, who was both a dentist and amateur boxer, subsequently refined the design of the gum shield and made them from vella rubber. ${ }^{1}$ In the United States, the first mouthguard was probably manufactured by Thomas Carlos, a Chicago dentist, in $1916 .^{14}$

By the 1930s, mouthguards were part of the standard boxers' equipment and have remained so since that time. Jack Dempsey and Gene Tunney, before the second world war, were probably the last of the heavyweight champions to fight without a mouthpiece.

\section{Types of mouthguard}

There are several distinct types of mouthguard. The simplest are the stock mouthguards, which may be purchased from sporting goods stores. The second type are the mouth formed or boil and bite guards, which are heated and immediately worn by the athlete allowing some adaptation to the dentition to occur. The more complex mouthguards are custom made and come in several types but all require an impression cast of the patient's dentition as the initial step and the guard is made on this cast. The simplest of these is a vacuum formed guard made from a single layer of poly(vinyl acetate)/polyethylene. More complex designs incorporate multiple layers or laminations of material, which are sandwiched together under high pressure and high temperature to form the final unit. This technique allows sport specific designs such as incorporating hard inserts over the incisors for ball or missile sports or the use of more shock absorbing material for collision sports.

In general terms, a custom fitted design is necessary to ensure retention of the mouthguard in collision or contact sports. The simpler designs do not afford much protection, tend to fit poorly, and often interfere with breathing and speech. Their advantage lies in their cheap cost and widespread availability. At community level, these are often the main type of mouthguard in use. ${ }^{5}$

Unfortunately there are no acceptable international standards for mouthguards, which makes the comparison between studies difficult. Intuitively one would expect a laminated custom fitted guard to offer more protection, at least to the teeth, but there is no way of comparing the guards reported in different studies. The manufacture of mouthguards and the capabilities of their materials have been reviewed, and readers are directed to these sources for more specific information. ${ }^{6}$

\section{Evidence for protective effect of mouthguards in sporting injury}

The evidence of injury protection by the use of mouthguards is mostly based on case series and retrospective injury surveys. Many authors quote a self reported history of dental injury before the use of mouthguards as the evidence for a protective effect. ${ }^{7-19}$

When injury surveys of individual teams are reported, the numbers of injuries are generally too low to draw adequate conclusions from the use of mouthguards. In a large cross sectional study of university rugby, no significant protective effect for any type of injury was shown in mouthguard users. ${ }^{20}$ Other authors, however, have shown different results. In a questionnaire study of high school basketball, wearers of mouthguards had a 10-fold reduction in dental injuries compared with non-wearers. Most of these injuries were lip lacerations, and no difference was found in relation to brain or spinal injury. $^{21}$

\section{Evidence for concussion prevention by mouthguards}

Although many authors claim that mouthguards offer an effective means of preventing concussion and spinal injuries, ${ }^{11}{ }^{22-24}$ the evidence for this statement is limited. Two papers are usually cited to support this contention, and these deserve particular analysis. ${ }^{25} 26$

The first is by Stenger et $a l,{ }^{26}$ who claimed benefit for both head and cervical spinal injuries by mouthguard use. ${ }^{26}$ The authors reported their experience of a season of gridiron football by the Notre Dame University team. In this paper, they anecdotally reported five cases of their experience in which mouthguard use had abolished the symptoms of Meniere's disease, cervical nerve root compression, chronic "burners" (cervical radicular syndrome), dizzy spells/low back pain, and, in one case, repeated concussion. They also noted that there were "six or seven" players within the team who required cervical traction before matches and that the need for such traction was abolished by regular mouthguard use. In the football season, there were a total of 10 cases of concussion and four dental injuries, providing insufficient data for statistical analysis of protective effect.

The authors also showed that with a mouthguard in situ, there was an altered mandibular position on lateral skull radiographs, so that the condyles were distracted from their fossae. On this basis, the authors postulated that forces from mandibular impact applied to the head and neck would be attenuated, resulting in fewer injuries. Their evidence however, is at best speculative.

The second commonly cited paper is by Hickey et al, ${ }^{25}$ who showed in a cadaver model that a mouthguard could attenuate the forces applied to the head as the result of a blow on the point of the chin. ${ }^{25}$ Using an intracranial pressure transducer, a decrease of about $50 \%$ was noted in the amplitude of the intracranial pressure wave after impact. There are a number of methodological concerns with this study, such as the difference in skull compliance between a cadaveric skull and a live human skull and the use of a fixed skull in the experimental model, which has previously been shown to alter the nature of the brain injury sustained. ${ }^{27}$ 
Although an interesting observation, neither pure linear acceleration nor changes in intracranial pressure after impact is the basis for diffuse brain injuries such as concussion. This has been extensively studied in animal and human models. ${ }^{27-31}$ Intracranial pressure changes are, however, related to focal brain injuries such as contracoup injury. To give the authors credit, they did not claim a beneficial effect for concussion or other forms of brain injury but simply reported their observations. Subsequent authors, who cite this research, often uncritically, have attributed a significance to these findings that may not have been intended by the original authors.

\section{Conclusions}

The ability of mouthguards to protect against head and spinal injuries in sport falls into the realm of "neuromythology" rather than hard science. ${ }^{32}$ Reading the original studies cited as evidence for this effect reveals anecdotal claims that can best be described as bizarre rather than reflecting established medical principles. It is unlikely that a mouthguard would offer effective protection against brain or spinal cord injury, and the limited published data are not compelling in this regard nor does it accord with the known pathophysiology of such injuries.

At this stage, there is no convincing evidence to support a protective effect against any type of sporting injury. This is largely because studies with sufficient power have not yet been performed. Absence of proof is not proof of absence. It is critical that a randomised controlled trial of sufficient power is performed to answer this question so that sports clinicians can accurately advise athletes of safety issues and the best means of preventing injury.

PAUL MCCRORY

Neurologist and Sports Physician

Centre for Sports Medicine Research and Education and the Brain

Research Institute, University of Melbourne, Parkville, Victoria, Australia 3052

pmccrory@compuserve.com

1 Reed R. Origin and early history of the dental mouthpiece. $\mathrm{Br}$ Dent $\mathcal{F}$ 1994;77:478-90.

2 Jacobs W. When dentistry gave boxing the mouthguard. Oral Hygiene 1938; 28:1152-4.

3 Wehner P, Henderson D. Maximum prevention and preservation. Dent Clin North Am 1965;9:493-8.
4 Carlos T. The mouthguard in use. Oral Hygiene 1938;28:1580-1.

5 Banky J, McCrory P. Mouthguard use in Australian football. 7 Sci Med Sport 1999;2:20-9.

6 Kerr I. Mouthguards for the prevention of injuries in contact sports. Sports Med 1986;3:415-27.

7 Chapman P. The prevalence of orofacial injuries and the use of mouthguards in rugby league. Aust f Sci Med Sport 1985;17:15-18.

8 Chapman P. Prevalence of oro-facial injuries and the use of mouthguards in rugby union. Aust Dent $\mathcal{F}$ 1985;30:364-7.

9 Chapman P. Orofacial injuries and mouthguards: a study of the 1984 wallabies. Br F Sports Med 1985;19:93-5.

10 Chapman PJ. Orofacial injuries and the use of mouthguards by the 1984 Great Britain Rugby League touring team. Br F Sports Med 1985;19:34-6.

11 Chapman P. Prevention of orofacial sporting injuries in children and young adolescents. Aust f Sci Med Sport 1986;18:3-6.

12 Chapman P. The pattern of use of mouthguards in rugby league (a study of the 1986 Australian rugby league touring team). Br $\mathcal{F}$ Sports Med 1988;22: 98-100.

13 Chapman P. Players attitudes to mouthguards and prevalence of orofacial injuries in the 1987 US Rugby football team. Br $\mathcal{F}$ Sports Med $1989 ; 17: 690-1$.

14 Chapman P. Orofacial injuries and international rugby players attitudes to mouthguards. Br F Sports Med 1990;24:156-8.

15 Chapman P. Attitudes to mouthguards and prevalence of orofacial injuries in international rugby: a study of the 1990 Wallabies. Aust $\mathcal{F}$ Sci Med Sport 1991;22:113-15

16 Chapman P, Nasser B. Attitudes to mouthguards and prevalence of oro-facial injuries in four teams competing at the second rugby world cup. Br F Sports Med 1993;27:197-9.

17 Stokes A, Chapman P. Mouthguard, dental trauma and the 1990 All Blacks. New Zealand Fournal of Sports Medicine 1991;19:66-7.

18 Kay E, Kakarla P, Macleod D, et al. Orofacial and dental injuries in club rugby players. Br f Sports Med 1990;24:271-3.

19 Jennings D. Injuries sustained by users and non-users of gum shields in local rugby union. Br F Sports Med 1990;24:159-65.

20 Blignaut J, Carstens I, Lombard C. Injuries sustained in rugby by wearers and non-wearers of mouthguards. Br f Sports Med 1987;21:5-7.

21 Maestrello-deMoya M, Primosch R. Orofacial trauma and mouth protector wear among high school varsity basketball players. If Dent Child 1989;36:36-9.

22 Chapman P. Mouthguards in sport. Sport Health 1983;1:13-15.

23 Chapman P. Concussion in contact sports and importance of mouthguards in protection. Aust $\mathcal{F}$ Sci Med Sport 1985;3:170-4.

24 Chapman P. Mouthguards and the role of sporting team dentists. Aust Dent f 1989;34:36-43.

25 Hickey J, Morris A, Carlson L, et al. The relation of mouth protectors to cranial pressure and deformation. F Am Dent Assoc 1967;74:735-40.

26 Stenger J, Lawson E, Wright J, et al. Mouthguards: protection against shock to the head, neck and teeth. F Am Dent Assoc 1964;69:273-81.

27 Denny-Brown D, Russell WR. Experimental cerebral concussion. Brain $1941 ; 64: 93-163$.

28 Gennarelli TA. Mechanisms of brain injury. F Emerg Med 1993;11(suppl 1):5-11

29 Ommaya AK, Gennarelli TA. Cerebral concussion and traumatic unconsciousness. Correlation of experimental and clinical observations of blunt head injuries. Brain 1974;97:633-54

30 Ommaya A. Head injury mechanisms and the concept of preventative management: a review and critical synthesis. F Neurotrauma 1995;12:52746.

31 Ommaya A. Biomechanical aspects of head injuries in sports. In: Jordan B, Tsaris P, Warren R, eds. Sports Neurology. Rockville, Maryland: Aspen Publishers Inc, 1990

32 McCrory P. The eighth wonder of the world: the mythology of concussion management. Br f Sports Med 1999;33:136-8.

Please note that the editorial office of British fournal of Sports Medicine has moved. Please send all future communications to: Dr Paul McCrory, British fournal of Sports Medicine, Centre for Sports Medicine Research \& Education, School of Physiotherapy Level 1, 200 Berkeley Street, Parkville, Victoria 3052, Australia. Tel: +61 38344 4118; Fax: +61 38344 3771; Email: jemcki@unimelb.edu.au 


\section{Expression of concern about content of which Dr Paul McCrory is a single author}

This paper is authored by Dr Paul McCrory. During 2021 and 2022 there was an investigation by BJSM and BMJ which found that some of his work was the product of publication misconduct. Such misconduct includes plagiarism, duplicate publication, misquotation and misrepresentation in publications in respect of which he was listed as the sole author. ${ }^{1}$ We are placing a notice to readers on all content in relation to which he is identified as the sole author to alert them to the conclusions of our investigation.

(C) Author(s) (or their employer(s)) 2022. No commercial re-use. See rights and permissions. Published by BMJ.

Br J Sports Med 2022;0:1. doi:10.1136/bjsports-2022-106408eoc

D) Check for updates

\section{REFERENCE}

1 Macdonald H, Ragavooloo S, Abbasi K. Update into the investigation of former BJSM editor-in-chief Paul McCrory. Br I Sports Med 2022. 